\title{
COUGH
}

\section{Reduced $\mathrm{pH}$ and chloride levels in exhaled breath condensate of patients with chronic cough}

\author{
A Niimi, L T Nguyen, O Usmani, B Mann, K F Chung
}

Thorax 2004;59:608-612. doi: 10.1136/thx.2003.012906

See end of article for authors' affiliations

.....................

Correspondence to: Professor K F Chung, Department of Thoracic Medicine, National Heart and Lung Institute, Imperial College, Dovehouse Street, London SW3 6LY, UK; f.chung@imperial.ac.uk

Received 14 July 2003 Accepted 26 January 2004
Background: Increased hydrogen and reduced chloride ionic environments of the airways are conducive to the stimulation of cough. However, the constituents of the local milieu of the airways of patients with chronic cough are unknown.

Methods: The $\mathrm{pH}$ and chloride levels in exhaled breath condensate and capsaicin cough threshold (C5) were measured in 50 patients with chronic cough and in 16 healthy controls. $\mathrm{pH}$ and chloride measurements were repeated after capsaicin challenge in those with cough. The cause of cough was asthma $(n=13)$, postnasal drip/rhinitis $(n=7)$, gastro-oesophageal reflux $(n=5)$, bronchiectasis $(n=5)$, but remained unidentified in 20 .

Results: Compared with controls, patients with chronic cough had lower $\mathrm{pH}$ (mean 7.9 v 8.3, 95\% $\mathrm{Cl}$ of difference -0.5 to $-0.2, \mathrm{p}<0.0001$ ), chloride levels (median $4 \vee 6 \mathrm{mmol} / \mathrm{l}, 95 \% \mathrm{Cl}-3.1$ to -0.2 , $\mathrm{p}=0.007$ ), and $\mathrm{C} 5$ (median $3.9 \vee 125 \mu \mathrm{M}, 95 \% \mathrm{Cl}-270.0$ to $-17.6, \mathrm{p}=0.002$ ). The $\mathrm{pH}$ levels were different in the six subgroups including controls, and were reduced in all diagnostic subgroups of patients with cough compared with controls but did not differ between them. Chloride levels were significantly different in the six subgroups but were lower than controls in only the gastro-oesophageal reflux subgroup. There was a weak but significant correlation between chloride levels and C5 when all participants were analysed together, but not between $\mathrm{pH}$ and $\mathrm{C} 5$ or chloride levels. $\mathrm{pH}$ and chloride levels did not change after capsaicin challenge.

Conclusions: The epithelial lining fluid of patients with chronic cough has a reduced $\mathrm{pH}$ and reduced chloride levels which could contribute to the enhanced cough reflex.
$\mathrm{C}$ hronic cough is a common clinical problem. ${ }^{1}$ Asthma postnasal drip (PND) or rhinitis, and gastro-oesophageal reflux (GOR) have been recognised by many investigators as the clinical conditions most commonly related to chronic cough. ${ }^{2}$ However, in a significant proportion of patients with chronic cough no associated clinical conditions can be identified despite thorough investigations and empirical treatment. ${ }^{3-5}$

Many of the clinical conditions related to chronic cough are characterised by increased cough sensitivity to inhaled tussive agents, ${ }^{16}$ although other conditions such as asthma or bronchiectasis may not share this feature. ${ }^{6}$ An acidic environment of the airway surface liquid may be causally related to the cough hypersensitivity. Exposure to acidic solutions causes action potential discharge in A $\delta$ fibres and $\mathrm{C}$ fibres of airway afferent nerves in guinea pig, both of which mediate the cough reflex. ${ }^{7}$ Inhalation of acidic solutions such as citric acid or acetic acid causes coughing in healthy humans or laboratory animals in vivo in a $\mathrm{pH}$ dependent manner. ${ }^{8-10}$ Various features of chronic inflammation may be present in the airways of patients with chronic cough of different causes, ${ }^{3}{ }^{41-13}$ and inflammation may cause a decrease in extracellular $\mathrm{pH}^{14}$ Endogenously reduced $\mathrm{pH}$ may therefore be involved in the pathogenesis of chronic cough or cough hypersensitivity. In addition, the tussive properties of low $\mathrm{pH}$ are potentiated by the lack of chloride in citric acid induced cough. ${ }^{8}$ Aqueous solutions without or containing only low levels of chloride ions when inhaled as aerosols have been found to stimulate cough. A doseresponse relationship between decreasing chloride levels and increasing cough has been shown. ${ }^{15}$ This may be independent of the $\mathrm{pH}$ of the inhaled solutions. ${ }^{8}$ Despite these observations, it is unknown whether the local milieu of the airways of patients with chronic cough has lowered $\mathrm{pH}$ or chloride levels.

Analysis of exhaled breath condensate (EBC) has been used as a non-invasive method for evaluating the lining fluid of the lower respiratory tract. ${ }^{16}$ Measurement of $\mathrm{pH}$ in EBC has recently been reported in several airway diseases including asthma, chronic obstructive pulmonary disease, bronchiectasis, and cystic fibrosis. ${ }^{17-19}$ We therefore collected EBC from adult patients presenting with chronic cough and healthy controls and measured their $\mathrm{pH}$ and chloride levels. These results were compared with the cough sensitivity measured by inhalation of capsaicin. The $\mathrm{pH}$ and chloride levels were also compared in diagnostic subgroups of cough, which may involve different pathophysiological features such as different types of airway inflammation. ${ }^{3}{ }^{11-13}$

\section{METHODS}

\section{Subjects}

Fifty consecutive patients with chronic cough of at least 8 weeks' duration referred during a 13 month period were studied. All were non-smokers. Diagnostic investigations included chest radiography, pulmonary function testing, methacholine challenge, 24 hour oesophageal pH monitoring, and chest and sinus computed tomography. ${ }^{1}$

Patients with methacholine $\mathrm{PC}_{20} \leqslant 4 \mathrm{mg} / \mathrm{ml}$, diurnal variation in peak expiratory flow $(\mathrm{PEF}) \geqslant 20 \%$, or an increase in forced expiratory volume in 1 second $\left(\mathrm{FEV}_{1}\right)$ of $\geqslant 15 \%$ after $\beta$ agonist, and a cough response to inhaled corticosteroid and bronchodilator therapy were diagnosed as having asthma

Abbreviations: $\mathrm{C} 2$ and $\mathrm{C} 5$, concentration of capsaicin causing $\geqslant 2$ or $\geqslant 5$ coughs; EBC, exhaled breath condensate; GOR, gastrooesophageal reflux; PND, postnasal drip 
which was responsible for the chronic cough. Cough was the sole or predominant symptom (cough variant or cough predominant asthma). Chronic cough due to gastro-oesophageal reflux (GOR) was diagnosed by 24 hour oesophageal $\mathrm{pH}$ monitoring and efficacy of a 12 week course of proton pump inhibitor and dietary changes. Chronic cough was attributed to postnasal drip (PND)/rhinitis when symptoms and an objective diagnosis of PND and/or rhinitis were present and nasal corticosteroids and/or anticholinergics were effective against the cough. Bronchiectasis was considered when patients had productive cough and typical findings of bronchiectasis on high resolution computed tomography. Coughing in such patients responded to some extent to antibiotics and/or chest physiotherapy. Some patients had no identifiable cause(s) of cough despite additional investigations including bronchoscopy and therapeutic trials for asthma, GOR, and PND/rhinitis.

Sixteen normal volunteers, all non-smokers, were also studied. The study was approved by the ethics committee of our institution. All subjects gave informed consent to participate in the study.

\section{Collection and measurement of EBC}

Subjects breathed tidally for 10 minutes, wearing a nose clip, into the special chamber of a condenser (Ecoscreen, Jaeger, Hoechberg, Germany) which froze the exhaled water vapour to $-20^{\circ} \mathrm{C}$. The collected condensate was immediately stored at $-70^{\circ} \mathrm{C}$.

$\mathrm{pH}$ was measured using a model $350 \mathrm{pH}$ meter (Jenway, Dunmow, UK). Before measurement, defrosted EBC samples were de-aerated with argon $(350 \mathrm{ml} / \mathrm{min})$ for 10 minutes. ${ }^{17}$ In a preliminary measurement of EBC from 19 subjects ( 11 controls and eight with cough), defrosted and de-aerated samples showed slightly but significantly higher $\mathrm{pH}$ than corresponding fresh unfrozen and de-aerated samples from the same subject. However, the $\mathrm{pH}$ of fresh and defrosted samples showed a good correlation $(r=0.91, \mathrm{p}=0.0001)$.

Chloride was measured using an ion-specific electrode (Bayer/Chiron model $644 \mathrm{Na} / \mathrm{K} / \mathrm{Cl}$ Analyser, Chiron Diagnostics, Sudbury, UK). Since the chloride levels of EBC were much lower than those of serum or urine, we adopted a method for sweat chloride measurement using 644 Sweat Diluent (Bayer Diagnostics Manufacturing Ltd, Sudbury, UK) with which the EBC samples were diluted 1:1 to bring the sample chloride levels into the measuring range of the ionspecific electrode. Linear regression analysis of the chloride levels of 48 sweat samples obtained by this method and those obtained by standard colometry showed a slope of 1.04, intercept of -1.43 , and correlation coefficient of 0.993 $(p<0.0001)$ by in-house testing by the manufacturer. The data obtained by the electrode were doubled because the samples were originally diluted $1: 1$. When the chloride level was below $2 \mathrm{mmol} / \mathrm{l}$, it was arbitrarily set at $0 \mathrm{mmol} / \mathrm{l}$ for calculation of the difference between groups.

\section{Capsaicin challenge}

As described previously, ${ }^{20}$ coughs were counted for 1 minute after single breath inhalation of saline and capsaicin solutions (Sigma-Aldrich, St Louis, MO, USA) of increasing concentrations $(0.98-500 \mu \mathrm{M})$. They were generated from a dosimeter (PK Morgan Ltd, Gillingham, UK) set at a dosing period of 1 second. This was continued until five or more coughs were induced. The concentration of capsaicin causing two or more coughs and five or more coughs were denoted C2 and $\mathrm{C} 5$, respectively. ${ }^{20}$

\section{Study design}

EBC collection, spirometry, and capsaicin challenge were performed on the same day in this order. In 41 patients EBC collection was repeated immediately after capsaicin challenge. In seven healthy subjects and 15 with chronic cough the $\mathrm{pH}$ of frozen and defrosted EBC samples was measured before and after de-aeration with argon.

\section{Statistical analysis}

Data were expressed as mean (SD) or median (range) and analysed using StatView 4.5 (Abacus Concepts, Berkeley, CA, USA). Unpaired $t$ tests or Mann-Whitney U tests were used to compare the two groups. Multiple group comparisons were performed using ANOVA and Fisher's PLSD tests, KruskalWallis and Mann-Whitney $U$ tests with Bonferroni/Dunn correction or $\chi^{2}$ test. The effect of the interventions on $\mathrm{pH}$ and chloride levels was analysed using the paired $t$ test or Wilcoxon signed rank test. Pearson's correlation test or Spearman's rank correlation test were used to determine correlations. $p$ values of $<0.05$ were considered significant.

\section{RESULTS}

\section{Characteristics of subjects}

The characteristics of patients with chronic cough and healthy controls are summarised in table 1. All patients had a normal chest radiograph. The mean (SD) duration of coughing was 10.3 (7.3) years. Thirteen patients were diagnosed as having asthma, seven PND/rhinitis, five GOR, five bronchiectasis, but 20 patients had no identifiable causes. Age but not sex distribution, duration of cough, or $\mathrm{FEV}_{1}$ was significantly different between the subgroups.

\section{Cough sensitivity and $\mathrm{pH}$ or chloride levels in EBC of controls and patients}

The patients with chronic cough had a C2 of 1.95 (0.98250) $\mu \mathrm{M}, \mathrm{C} 5$ of $3.9(0.98->500) \mu \mathrm{M}, \mathrm{pH}$ values of 7.91 (0.30), and chloride titres of $4(<2-12) \mathrm{mmol} / \mathrm{l}$ (table 1 ) which were significantly lower than the control values $(\mathrm{pH}$ $8.26(0.20)$, chloride $6(2-8))$ : mean difference of $\mathrm{C} 2$ $-43.4 \mu \mathrm{M}(95 \% \mathrm{CI}$ of difference -90.9 to -4.1$), \mathrm{p}=0.049$; mean difference of C5 $-143.8 \mu \mathrm{M}(95 \% \mathrm{CI}-270.0$ to -17.6$)$, $\mathrm{p}=0.002$; mean difference of $\mathrm{pH}-0.35(95 \% \mathrm{CI}-0.51$ to $-0.19), \quad \mathrm{p}<0.0001$; mean difference of chloride level $-1.7 \mathrm{mmol} / \mathrm{l}(95 \% \mathrm{CI}-3.1$ to -0.2$), \mathrm{p}=0.007$.

$\mathrm{C} 5, \mathrm{pH}$, and chloride titres in EBC were significantly different among the six groups including the five subgroups of patients with cough (table 1). By multiple comparison, C5 was lower in patients with PND/rhinitis, GOR, and those without identifiable causes than controls, but not in patients with asthma or bronchiectasis (table 1). The pH levels in EBC were lower in all subgroups of chronic cough than in controls. There were, however, no differences between these subgroups although comparison of small subgroups may lack statistical power (fig 1). Chloride levels showed a substantial overlap between subgroups but were significantly different between patients with GOR and controls by multiple comparison (fig 2).

A small number of patients with asthma, PND/rhinitis, GOR, or cough of unidentified cause were receiving medications at the time of the study (table 1). However, the results of $\mathrm{C} 2, \mathrm{C} 5, \mathrm{pH}$ and chloride levels did not differ between patients receiving treatment and those without treatment for each subgroup (data not shown), although the number of patients in most subgroups was too small for meaningful statistical analysis. Neither the $\mathrm{pH}$ nor chloride levels in EBC changed before and after capsaicin challenge in 41 patients with chronic cough in whom EBC was repeatedly collected $(7.96(0.30) v 7.98(0.31), \mathrm{p}=0.76$ and $4(<2-10) \mathrm{mmol} / \mathrm{l} v 4$ $(<2-8) \mathrm{mmol} / \mathrm{l}, \mathrm{p}=0.19$, respectively).

\section{Correlation between data}

The chloride levels in EBC showed a weak but significant correlation with C5 when all participants were analysed 
Table 1 Characteristics and outcomes in healthy controls and patients with chronic cough

\begin{tabular}{|c|c|c|c|c|c|c|c|}
\hline & \multirow[b]{2}{*}{$\begin{array}{l}\text { Healthy controls } \\
(n=16)\end{array}$} & \multicolumn{5}{|l|}{ Chronic cough } & \multirow{2}{*}{$\begin{array}{l}\text { p values } \\
\text { (ANOVA, } \\
\text { Kruskal-Wallis } \\
\text { test or } \chi^{2} \text { test) }\end{array}$} \\
\hline & & $\begin{array}{l}\text { Asthma } \\
\text { ( } n=13 \text { ) }\end{array}$ & $\begin{array}{l}\text { PND/rhinitis } \\
(n=7)\end{array}$ & $\begin{array}{l}\text { GOR } \\
(n=5)\end{array}$ & $\begin{array}{l}\text { Bronchiectasis } \\
(n=5)\end{array}$ & $\begin{array}{l}\text { Unidentified cause } \\
(n=20)\end{array}$ & \\
\hline Age (years) & $43(8)$ & 44 (17) & $55(7)^{*}$ & $59(5) \dagger, \ddagger$ & $62(18) \dagger, \ddagger, \S$ & $53(12) \dagger, 1)$ & 0.005 \\
\hline$M / F$ & $4 / 12$ & $6 / 7$ & $0 / 7$ & $1 / 4$ & $1 / 4$ & $3 / 17$ & 0.23 \\
\hline Duration of cough (years) & - & $5.4(5.5)$ & $11.4(8.3)$ & $9.8(5.5)$ & $10.7(5.1)$ & $13.0(7.8)$ & 0.08 \\
\hline Patients on medication & - & $\begin{array}{l}3 \text { (2 ICS, } 1 \text { ICS } \\
+ \text { LABA) }\end{array}$ & $\begin{array}{l}3 \text { (2 NCS, } 1 \text { nasal } \\
\text { anticholinergic) }\end{array}$ & I 1 (PPI) & 0 & $\begin{array}{l}6 \text { (2 NCS, } 2 \text { oral } \\
\text { antihistamine, } 1 \mathrm{NCS} \\
+ \text { PPI, } 1 \text { ICS + PPI) }\end{array}$ & 0.54 \\
\hline $\mathrm{FEV}_{1}$ (\% predicted) & $100(12)$ & $91(16)$ & $88(20)$ & $106(18)$ & $98(24)$ & $101(20)$ & 0.27 \\
\hline $\mathrm{C} 2(\mu \mathrm{M})$ & $7.8(0.98-500)$ & $3.9(0.98-250)$ & $0.98(0.98-15.6)$ & $0.98(0.98-1.95)$ & $3.9(0.98-125)$ & $1.47(0.98-31.3)$ & 0.13 \\
\hline C5 ( $\mu \mathrm{M})$ & $125(1.95->500)$ & $31.3(0.98-250)$ & $3.9(0.98-15.6)^{* *}$ & $\begin{array}{l}1.95 \\
(0.98-15.6)+\dagger\end{array}$ & $3.9(0.98-500)$ & $2.93(0.98->500)+\dagger$ & 0.009 \\
\hline
\end{tabular}

Data are expressed as mean (SD) or median (range).

${ }^{*} p=0.03, p=0.01,{ }^{* *} p=0.005,+7 p=0.003 v$ control.

$\neq \mathrm{p}=0.03, \S p=0.01,|| p=0.04 v$ patients with asthma.

$\mathrm{PND}=$ postnasal drip; $\mathrm{GOR}=$ gastro-oesophageal reflux; ICS = inhaled corticosteroids; $\mathrm{NCS}=$ nasal corticosteroids; $\mathrm{LABA}=$ long acting $\beta$ agonists; $\mathrm{PPI}=$ proton pump inhibitors; $F E V_{1}=$ forced expiratory volume in 1 second; $C 2, C 5=$ lowest concentration of capsaicin that induced $\geqslant 2$ or $\geqslant 5$ coughs, respectively; $\mathrm{EBC}=$ exhaled breath condensate.

together $(\mathrm{n}=66, r=0.30, \mathrm{p}=0.01)$. However, there was no such correlation between $\mathrm{pH}$ titres in EBC and C5 $(r=-0.11$, $\mathrm{p}=0.35)$ or chloride levels $(r=0.10, \mathrm{p}=0.38)$. C2 did not correlate with chloride or $\mathrm{pH}$ titres in EBC (data not shown). No correlation was found between pH titres, chloride levels, and $\mathrm{C} 2$ or $\mathrm{C} 5$ when the analysis was confined to patients with cough, controls, or any cough subgroup (data not shown).

\section{Effect of argon de-aeration of EBC samples on $\mathrm{pH}$ titres}

After de-aeration of defrosted EBC samples the $\mathrm{pH}$ rose significantly from $7.06(0.32)$ to $8.05(0.26)$, mean difference 0.99 (95\% CI 0.87 to 1.12$), \mathrm{p}<0.0001$. The correlation between $\mathrm{pH}$ before and after de-aeration was significant $(\mathrm{n}=22, r=0.57, \mathrm{p}=0.005)$. The $\mathrm{pH}$ of EBC before deaeration was significantly lower in patients with cough $(\mathrm{n}=15)$ than in controls $(\mathrm{n}=7)(6.95(0.29) \vee 7.29(0.25)$, mean difference 0.35 (95\% CI 0.08 to 0.61$), p=0.01$ ) as well as those of de-aerated EBC (data not shown).

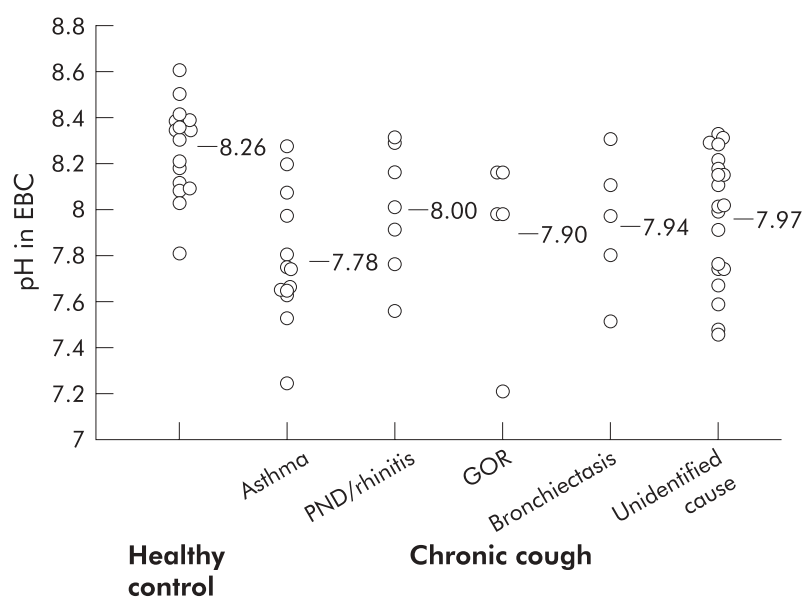

Figure 1 Distribution of $\mathrm{pH}$ titres in exhaled breath condensate (EBC) of individual groups. There was a significant difference between the six subgroups $(p=0.001$, ANOVA). By multiple comparison, all subgroups of chronic cough had lower $\mathrm{pH}$ titres than controls $(\mathrm{p}<0.0001 \mathrm{for}$ asthma, $p=0.04$ for postnasal drip (PND)/rhinitis, $p=0.01$ for gastrooesophageal reflux (GOR), $p=0.02$ for bronchiectasis, $p=0.002$ for those with unidentified cause) but there was no difference between the subgroups. Horizontal bars represent means.

\section{DISCUSSION}

We have shown that EBC of patients with chronic persistent cough is more acidic and has lower chloride levels than EBC of non-coughing normal subjects. The change in $\mathrm{pH}$ (on average, a halving of hydrogen ions) was not large but may be sufficient to stimulate cough. The changes in chloride ions were much more modest but correlated weakly but significantly with capsaicin cough sensitivity. Because these changes could favour the activity of airway sensory nerves such as cough afferents, our findings indicate that they may contribute to the enhanced cough reflex.

We studied patients referred to our cough clinic from a wide area of southern UK, most of whom had been seen by other colleagues and received treatment. The mean duration of coughing in these patients was more than 10 years. Not surprisingly, in a large proportion of patients $(40 \%)$ we could not identify a cause for the chronic cough, which contrasts with other series. ${ }^{2}$ Irrespective of the cause of chronic cough, the $\mathrm{pH}$ levels were lower than in healthy controls of a similar order of magnitude. Even in the five patients with GOR (four of whom were not receiving treatment), there was a similar

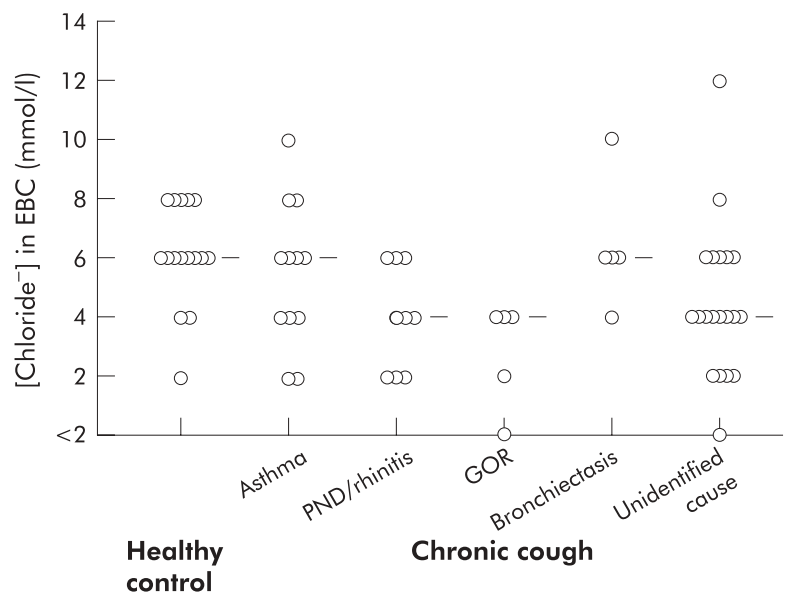

Figure 2 Distribution of chloride titres in exhaled breath condensate (EBC) of individual groups. There was a significant difference between the six subgroups ( $p=0.01$, Kruskal-Wallis test). By multiple

comparison, only the chronic cough subgroup associated with gastrooesophageal reflux (GOR) had significantly lower chloride titres than the control group $(p=0.004)$, and there was no difference between the subgroups. Horizontal bars represent medians. PND = postnasal drip. 
order of $\mathrm{pH}$ reduction. Although the number of patients in the subgroups may be too small to draw a definite conclusion, these results argue against a direct contribution of acid from the stomach into the airway lining fluid. ${ }^{21} \mathrm{~A}$ smaller reduction in chloride was noted only in patients with GOR, but there was a weak but significant correlation between the chloride levels and cough sensitivity when all subjects were analysed together. Although these changes in $\mathrm{pH}$ and chloride may be modest, the interaction between acid and low chloride contents in the coughing mechanism might be synergistic. $^{8}$

The measurement of $\mathrm{pH}$ in EBC samples was performed after de-aeration with argon, as initially described by Hunt and colleagues. ${ }^{17}$ We found that de-aeration with argon causes an increase in $\mathrm{pH}$ of 1 . Although de-aeration with argon has been used as the "gold standard" method for measurement of $\mathrm{pH}$ in $\mathrm{EBC},{ }^{17} 1822$ the exact effect of deaeration on the $\mathrm{pH}$ of $\mathrm{EBC}$ has not previously been described. ${ }^{17} 1822$ To our knowledge, our study is the first to show a significant rise in $\mathrm{pH}$ immediately after argon deaeration. Relatively larger differences in $\mathrm{pH}$ were reported than in other published studies of $\mathrm{pH}$ in EBC. In a cross sectional study Hunt and colleagues found that the mean $\mathrm{pH}$ of the EBC in patients with acute asthma was 5.23 compared with a mean of 7.80 in a control group with stable asthma. ${ }^{17}$ Tate and colleagues ${ }^{19}$ found a mean $\mathrm{pH}$ of EBC not de-aerated with argon of 5.88 in patients with stable cystic fibrosis compared with 6.15 in healthy subjects and 5.32 in patients with a cystic fibrosis exacerbation. It has been postulated that the acidification is related to the underlying airway inflammation which occurs during acute exacerbations of asthma or cystic fibrosis. ${ }^{17}{ }^{19}$ In acute asthmatic inflammation glutaminase activation may regulate $\mathrm{pH} .{ }^{22}$ In cystic fibrosis chronic acidification may also be related to reduced bicarbonate secretion which is characteristic of the lung in this condition. ${ }^{19}$ The cause of the reduced $\mathrm{pH}$ in our patients with chronic cough is unclear, but changes in the inflammatory component of the mucosa or in the mucus content may contribute. $^{34}{ }^{11-132324}$

Reduced pH values in EBC have been associated more with neutrophilic inflammation than with eosinophilic inflammation. ${ }^{18}$ However, the $\mathrm{pH}$ of our subgroups characterised by neutrophilic inflammation (bronchiectasis and undiagnosed cases $^{3}$ ) did not differ significantly from that of asthmatics characterised by eosinophilic inflammation. ${ }^{11-13} 2324$

The EBC of our control subjects had a slightly higher $\mathrm{pH}$ than was found in two previous studies which also used argon de-aeration. In these previous studies mean $\mathrm{pH}$ values of 7.65 and 7.57 were reported. ${ }^{17}{ }^{18}$ This might be due to freezing and defrosting of samples in our study, but this process does not appear to have influenced the interpretation of the results because the $\mathrm{pH}$ values of fresh unfrozen samples and corresponding defrosted samples obtained from a subset of subjects were highly correlated. The $\mathrm{pH}$ of epithelial lining fluid has been reported to be between 6.5 and 7.5 in healthy adults or children as measured by direct application of microelectrodes to the trachea or proximal bronchi. ${ }^{25} 26$ The pH of EBC of healthy subjects in three published reports ${ }^{17-19}$ as well as in our study is outside the range of directly measured lower airway $\mathrm{pH}^{25}{ }^{26}$ Moreover, in our analysis of seven healthy subjects the $\mathrm{pH}$ of pre-deaerated EBC (mean 7.29) was closer to the reported values of "physiologic" pH described above ${ }^{25} 26$ than to the $\mathrm{pH}$ of deaerated EBC (mean 8.17). Processing and $\mathrm{pH}$ measurement of EBC may therefore require further validation, including a comparison between the $\mathrm{pH}$ of $\mathrm{EBC}$ and that of direct measurement of the airway surface liquid. ${ }^{17}$ The effect of argon de-aeration needs to be studied more closely.
A decrease in the $\mathrm{pH}$ can cause activation of $\mathrm{A} \delta$ fibres and C fibres in the airways of guinea pigs and rats. ${ }^{72}$ This involves the capsaicin receptor VRl, since protons can increase the openings of the VRl ion channel. ${ }^{28} \mathrm{VRl}$ is a sensory neurone specific ion channel that is potentiated by extracellular proton within the $\mathrm{pH}$ range encountered during tissue acidosis. For example, during the relatively small change in $\mathrm{pH}$ from 7.6 to 7.0 there is already potentiation of heat activated currents in the VRI receptor, ${ }^{29}$ indicating the potential for reduction in $\mathrm{pH}$ to augment capsaicin cough sensitivity. Low chloride stimuli are known to cause cough ${ }^{8} 15$ and to stimulate tracheal $\mathrm{A} \delta$ and $\mathrm{C}$ fibres in guinea pig airways. ${ }^{30}$ On the other hand, the lower $\mathrm{pH}$ and chloride levels in the EBC in our patients could be a result-rather than the cause-of persistent cough. Coughing may stimulate mucus secretion and affect epithelial ion transport, ${ }^{31}$ possibly through cholinergic mechanisms. ${ }^{32}$ This may influence the levels of $\mathrm{pH}$ and chloride in the epithelial lining fluid. However, it is difficult to be sure from our results which is the cause and which is the effect. The fact that capsaicin induced cough did not change the $\mathrm{pH}$ or chloride in EBC may not support the notion that the cough is the cause, although capsaicin induced coughing is transient.

We did not find a significant relationship between the $\mathrm{pH}$ of EBC and capsaicin cough sensitivity. In a study in healthy subjects ${ }^{9}$ the cough response to various acids at similar $\mathrm{pH}$ correlated well but they did not correlate with the cough response to capsaicin, indicating different pathways for capsaicin and acid induced cough. ${ }^{9}$ In a recent study in patients with chronic cough, however, cough responses to capsaicin and citric acid showed a positive correlation. ${ }^{33}$ The underlying pathophysiology of chronic cough and the mechanism(s) of reduction in airway $\mathrm{pH}$ as observed in this study may not both be uniform in patients with a variety of conditions associated with chronic cough. This may also be the case in patients without identifiable causes of cough. Investigations conducted in a larger number of subjects with chronic cough of the same aetiology may reveal more clearcut relations.

Our study has some limitations. Objective measurements of cough using a visual analogue scale or cough recordings were not made so the relationship between cough frequency or severity and $\mathrm{pH}$ or chloride could not be ascertained. The controls were significantly younger than the patients with cough and this may have affected the results. However, the effect of age on airway $\mathrm{pH}$ or chloride is not known.

In conclusion, EBC of patients with chronic cough has reduced $\mathrm{pH}$ and chloride levels. While this may not be of diagnostic value, these observations may be important in explaining the pathophysiology of chronic cough or cough hypersensitivity. Modulation of lower $\mathrm{pH}$ and chloride in the local environment of the airways may be potentially promising as a treatment for chronic cough, especially in patients with intractable coughing requiring "non-specific" antitussive treatment. ${ }^{34}$ This needs to be clarified in further studies.

\section{ACKNOWLEDGEMENTS}

The authors thank Mr Michael Kemp, Department of Biochemistry, Royal Brompton and Harefield NHS trust for technical assistance in the measurement of chloride levels, and Sally Meah, Clare Kelly, Lynda Walker, and Justine Arbery for collecting exhaled breath condensate.

\section{Authors' affiliations}

A Niimi, L T Nguyen, O Usmani, B Mann, K F Chung, Department of Thoracic Medicine, National Heart and Lung Institute, Imperial College and Royal Brompton Hospital, London, UK 
Akio Niimi was supported by a grant from Kyoto University, Kyoto, Japan.

\section{REFERENCES}

1 Chung KF, Lalloo UG. Diagnosis and management of chronic persistent dry cough. Postgrad Med J 1996;72:594-8.

2 Irwin RS, Curley FJ, French CL. Chronic cough. The spectrum and frequency of causes, key components of the diagnostic evaluation, and outcome of specific therapy. Am Rev Respir Dis 1990;141:640-7.

3 Jatakanon A, Lalloo UG, Lim S, et al. Increased neutrophils and cytokines, TNF- $\alpha$ and IL- 8 in induced sputum of non-asthmatic patients with chronic dry cough. Thorax 1999:54:234-7.

4 Boulet L-P, Milot J, Boutet $M$, et al. Airway inflammation in nonasthmatic chronic cough. Am J Respir Crit Care Med 1994;149:482-9.

5 Morice AH. Epidemiology of cough. Pulm Pharmacol Ther 2002;15:253-9.

6 Choudry NB, Fuller RW. Sensitivity of the cough reflex in patients with chronic cough. Eur Respir J 1992;5:296-300.

7 Kollarik M, Undem BJ. Mechanism of acid-induced activation of airway afferent nerve fibres in guinea-pig. J Physiol 2002;543:591-600.

8 Lowry RH, Wood AM, Higenbottam TW. Effects of $\mathrm{pH}$ and osmolarity on aerosol-induced cough in normal volunteers. Clin Sci 1988;74:373-6.

9 Wong CH, Matai R, Morice AH. Cough induced by low pH. Respir Med 1999;93:58-61.

10 Laude EA, Higgins KS, Morice AH. A comparative study of citric acid, capsaicin and resinferatoxin on the cough challenge in guinea-pig and man. Pulm Pharmacol 1993;6:171-5

11 Niimi A, Amitani R, Suzuki K, et al. Eosinophilic inflammation in cough variant asthma. Eur Respir J 1998;1 1:1064-9.

12 Niimi A, Matsumoto $H$, Minakuchi $M$, et al. Airway remodelling in coughvariant asthma. Lancet 2000;356:564-5.

13 McGarvey LPA, Forsythe P, Heaney LG, et al. Bronchoalveolar lavage findings in patients with chronic nonproductive cough. Eur Respir J 1999; 13:59-65.

14 Sasse SA, Causing LA, Malligan ME, et al. Serial pleural fluid analysis in a new experimental model of empyema. Chest 1996;109:1043-8.

15 Ventresca PG, Nichol GM, Barnes PJ, et al. Inhaled furosemide inhibits cough induced by low chloride solution but not by capsaicin. Am Rev Respir Dis 1990; 142:143-6.

16 Kharitonov S, Barnes PJ. Exhaled markers of pulmonary disease. Am J Respir Crit Care Med 2000;163:1693-722.

17 Hunt JF, Fang K, Malik R, et al. Endogenous airway acidification. Implication for asthma pathophysiology. Am J Respir Crit Care Med 2000;161:694-9
18 Kostikas K, Papatheodouru G, Ganas K, et al. pH in breath condensate of patients with inflammatory airway diseases. Am J Respir Crit Care Med 2002; 165:1364-70

19 Tate S, MacGregor G, Davis M, et al. Airways in cystic fibrosis are acidified: detection by exhaled breath condensate. Thorax 2002:57:926-9.

20 Lalloo UG, Lim S, DuBois R, et al. Increased sensitivity of the cough reflex in progressive systemic sclerosis patients with interstitial lung disease. Eur Respir J 1998; 11:702-5.

21 Irwin RS, Madison JM, Fraire AE. The cough reflex and its relation to gastrooesophageal reflux. Am J Med 2000;108:73-8S.

22 Hunt JF, Erwin E, Palmer L, et al. Expression and activity of pH-regulatory glutaminase in the human airway epithelium. Am J Respir Crit Care Med 2002; 165:101-7.

23 Gibson PG, Fujimura M, Niimi A. Eosinophilic bronchitis: clinical manifestations and implications for treatment. Thorax 2002:57:178-82.

24 Brightling CE, Symon FA, Birring SS, et al. Comparison of airway immunopathology of eosinophilic bronchitis and asthma. Thorax 2003;58:528-32

25 Jayaraman S, Joo NS, Reitz B, et al. Submucosal gland secretion in airways from cystic fibrosis patients have normal $\left[\mathrm{Na}^{+}\right]$and $\mathrm{pH}$ but elevated viscosity. Proc Natl Acad Sci USA 2001;98:8119-23.

26 McShane D, Davies JC, Davies MG, et al. Airway surface pH in subjects with cystic fibrosis. Eur Respir J 2003;21:37-42.

27 Fox AJ, Urban L, Barnes PJ, et al. Effects of capsazepine against capsaicinand proton-evoked excitation of single airway $C$-fibres and vagus nerve from the guinea-pig. Neuroscience 1995;67:741-52.

28 Tominaga M, Caterina MJ, Malmberg AB, et al. The cloned capsaicin receptor integrates multiple pain-producing stimuli. Neuron 1998;21:531-43

29 Jordt S-E, Tominaga M, Julius D. Acid potentiation of the capsaicin receptor determined by a key extracellular site. Proc Natl Acad Sci USA 2000;97:8134-9

30 Fox AJ, Barnes PJ, Dray A. Stimulation of guinea-pig tracheal afferent fibres by non-isosmotic and low chloride stimuli and the effect of frisemide. J Physiol 1995;482:179-87.

31 Foster WM. Mucus hypersecretion and mucus clearance in cough. In: Chung KF, Widdicombe JG, Boushey HA. Cough: causes, mechanisms and therapy. Oxford: Blackwells, 2003:207-16.

32 Bennett WD, Chapman WF, Mascarella JM. The acute effect of ipratropium bromide bronchodilator therapy on cough clearance in COPD. Chest 1993; 103:488-95.

33 Kastelik JA, Thompson RH, Aziz I, et al. Sex-related differences in cough reflex sensitivity in patients with chronic cough. Am J Respir Crit Care Med 2002;166:961-4

34 Chung KF. Cough: potential pharmacological developments. Expert Opin Investig Drugs 2002;11:955-63. 